\title{
Research on the Innovation Mode of College Art Courses Based on New Media
}

\author{
Xiao Feng \\ Xi'an University, Xi'an Shaanxi, 710065 \\ Keywords: New Media; College Art Courses; Innovation \\ Abstract: The term of new media is no longer new to everyone. New media technologies \\ have been widely used in various fields and have had a profound impact on our work and \\ life. New media is a platform and a tool. College art courses can be organically aligned \\ with new media technologies in many ways. How to make full use of this technology to \\ realize the leap-forward development of college art courses is not only the need for the \\ development of college art courses, but also the inevitable trend of college curriculum \\ reform
}

\section{Introduction}

College art course is a practical and highly applied course. In recent years, with the development of Chinese economy and society, our demand for professional art talents is very large. At present, the main front of the cultivation of professional art talents in China is still various colleges and universities. However, in general, although the number of talents in colleges and universities in China has increased year by year, there is still a big gap between the quality of talent output and social needs. How to resolve this contradiction and to achieve a balance between talent cultivation ability and talent demand is the key link of Chinese education and teaching reform in the new era.

Any reform requires a certain platform and opportunity. New media technologies have made this reform possible. New media is a technology and an environment, and it is the product of a combination of high information and network. New media technology has penetrated into every aspect of our lives, and it has increasingly affected our work and life. New media technology uses its unique advantages to transform dull and boring information into lively content, thus achieving a leap in people's understanding. How to apply new media technology to college art courses, realize the innovative development of college art courses, and realize the perfect connection between college art courses and new media technologies is an important support for the transition from traditional education teaching mode to college art courses in the new era.

\section{The Shortcomings in the Current Art Course Teaching in Colleges and Universities}

After years of development, traditional college art courses have achieved good results in many places. However, with the development of the times, some links in the original teaching mode have been unable to adapt to the requirements of new teaching objectives, and even hinder the reform and development of education and teaching. The disadvantages of traditional college art teaching 
generally exist in the aspects of education teaching mechanism, methods, curriculum content setting, and evaluation system construction. Under the traditional system, the classroom is the only place for students to contact and learn knowledge. In the classroom, the teacher is in an absolute dominant position, and the knowledge is transmitted in one direction. In the past few years, although the traditional college art education teaching methods have also changed, such as the application of certain slides and multimedia technology. However, the classroom teaching has not been much changed, and it is still following the traditional routines and modes. Teachers and students have less communication in classroom teaching, and students' problems after class are hard to get timely answers. Under the existing education and teaching system, classroom teaching time is very limited. The teacher has to take care of the progress of the teaching and has to answer some questions about the problems in the classroom. The contradiction between teaching and learning is very prominent. In the teaching content, due to the limitations of the conditions, the teacher can not fully lecture the knowledge, and can only make a straightforward statement about the knowledge points. Students can only follow up the teacher's guidance, which greatly dampens the enthusiasm and initiative of students. Besides, our current assessment mechanism pays more attention to theoretical knowledge, and the assessment system for practice is relatively imperfect. One of the most important reasons why the traditional assessment mechanism has been used is that it can be carried out in a neat and easy-to-operate manner. In contrast, the assessment of practical ability is much more complicated. The assessment of practical ability requires complex standards and a more scientific system. In this regard, some colleges and universities have made some attempts and efforts, but the results have been minimal.

\section{The Advantages of New Media}

New media has a huge advantage, and this advantage is not only at the technical level. If we want to do a good job in the reform of college art course based on new media, we must have a deeper understanding of the characteristics of new media. New media technology has broken through the deficiency in traditional information technology in terms of communication methods and performance capabilities. The new media technology has a novel form and distinctive personality, and integrates the transmission of sound, image, video and other elements to make the expression of information flexible and efficient. Under the new media technology, the means of storing information has also been greatly improved. New media technology can be integrated with massive storage information, so that information acquisition and search can be carried out conveniently and efficiently. Finally, new media technologies have good interactivity. Under the new media technology, information can be transmitted in real time, and both parties can achieve timely communication and interaction.

Applying new media technology to college art courses can effectively improve the fun of college art courses teaching, and let teachers' teaching and students' learning break through time and space constraints. New media technology can strengthen the flexibility of art teaching in colleges and universities, break the obstacle of art teaching in traditional colleges and universities, and lead the art teaching in colleges to a new stage of development.

\section{Innovation of Teaching Methods of College Art Courses Based on New Media}

In the era of new media, we must do a good job in the innovation of the teaching methods of college art courses, mainly from the following aspects. 


\subsection{Innovate Concept}

The concept is the most critical part of guiding education and teaching. The reason why the innovation of the concept is in the first place is that there has been a certain gap in the teaching philosophy of our college art courses compared with foreign counterparts for a long time. Although new media technology have many advantages, they ultimately require human control and design. Therefore, if we do not touch the deep-seated ideas, it is difficult to integrate this technology with the needs of education and teaching. We must change the traditional education and teaching ideas to keep up with the pace of the times. We must be good at innovation, bold reform, forge ahead, and apply various advanced educational concepts and ideas to the reform of college art courses and to guide the innovation of teaching methods in college art courses. In recent years, many scholars and educators have made effective explorations and attempts in how to change the traditional education and teaching concepts in theory and practice, and achieved good results.

\subsection{Break through the Shackles of Regular Teaching Mode}

In the traditional teaching mode, teachers are the masters of the classroom, and they teach knowledge and information to students in a limited time. Teachers use cramming teaching methods, and students are passively accepted. Although this mode is widely criticized, it has been used. This kind of teaching model make students gradually lose their autonomy and unable to effectively improve their comprehensive ability and quality. New media technology have effectively extended the teaching in time and space. In recent years, micro-courses have developed into an important auxiliary means for the teaching of art courses in colleges and universities under the new media technology. Micro-courses are small courses designed for a certain teaching content and they often use video as the main carrier. Micro-courses record the wonderful teaching process that the teacher performs around a certain knowledge point inside and outside the classroom. The duration of micro-courses is generally short and often controlled within ten minutes. This is indeed a bit short compared to the traditional 45-minutes class. However, micro-courses are not small, and they play an extremely important role in the teaching of new media. With the popularization of network technology, especially the construction of campus network, the network is no longer a obstacle restricting the communication between teachers and students. The popularity of the campus network provides a good environment for the dissemination of micro-courses. Develop and utilize micro-courses fully, so that students can collect and learn course-related knowledge and information anytime and anywhere in the computer and mobile has become the core of many college education reform. The introduction of micro-courses fully mobilized the enthusiasm and initiative of students. It changes the teacher-led teaching mode to the student-independent learning mode. Students can find deficiencies in the study of micro-courses, sum up and improve, and even many students participate in the production of micro-courses. Through self-learning and independent thinking, students not only strengthen their theoretical knowledge, but also exercise their practical ability. Foreign studies have shown that the effective learning time of students in the classroom is often concentrated within the first twenty minutes of the course, after which students will reduce to varying degrees regardless of the effect or the attention of learning. The popularity of micro-courses fully compensates for the weaknesses of classroom teaching and overcomes the constraints of classroom teaching. In recent years, there are many cases in which the introduction of college art courses in flipping classrooms, and both have achieved good teaching results. Flipping classroom is another successful case of combining new media with college art courses. There are similarities and differences between flipping classrooms and micro-courses. The design of the flipping classroom is also student-centered, using multimedia and other information technology to drive the initiative and consciousness of students. The flipping classroom also fully considers the different levels of 
learning of students. In the learning, through the interaction of teachers and students, interaction between students, and group work, the roles that need to be undertaken by the majority of art teachers in the original classroom are distributed to students, and the initiative of learning is completely handed over to students. Since 2012, the practice and application of flipping classrooms have been deepened, and the teaching results obtained by them have been fully affirmed by the Ministry of Education. The Ministry of Education of China has listed the integration and development of information technology and education in the ten-year development plan as the direction and focus of education and teaching reform.

\subsection{Use New Media Technology to Mobilize Educational and Teaching Resources}

New media technology relies on network and information technology to achieve long-distance transmission and resource sharing of information. College art courses teaching relies on the new media technology, and it is necessary to fully integrate the related educational and teaching resources scientifically. The majority of teachers should fully explore and organize various educational and teaching resources. At the same time, teaching resources should be updated regularly. Besides, the majority of teachers should fully encourage students to participate in the integration of art courses education resources. Let students find the learning materials that they are interested in, and personally create multimedia resources that help them to learn, which will fully tap the potential of students in the interaction between teaching and learning.

\subsection{Use New Media Technology to Create A Good Learning Environment}

The application of new media technology has made it possible to create a good learning environment for art courses. How to create a good art learning environment in colleges and universities plays an important role in improving the ability of college students to improve their art. In the regular art teaching class, due to limitations of time and conditions, teachers can not present some background knowledge of art, painter experience and other information, and there is not much time for students to practice skills, which has caused many students low ability with high scores. New media technology can create a good learning environment for students through the use of technical means. Sound and images are the two most widely used methods of information transfer in new media technology. In addition, online resources such as art gallery, distance education system, and campus network classrooms under the new media can provide students with a very excellent art learning environment.

\section{Conclusion}

In the new historical period, especially in the stage of the progressive reform of education and teaching in colleges and universities in China, how to do a good job in the reform and innovation of college art courses is a matter of success or failure. College art courses are the basic course in the art field and occupy an important position in the entire higher education system. We must take the opportunity of reform and development, and forge ahead. Work hard on how to improve students' comprehensive ability, and let students translate their knowledge into their own abilities. New media technology is a broad platform. Therefore, we must give full play to its advantages and promote the healthy and steady development of college art courses.

\section{References}

[1] Xie Wu. Problems in Current Art Courses and Reform and Development Strategies [J]. Theoretical Discussion, 2013 (6). 
[2] Xiang Hongnian. Strategy and Practice Research on the Integration and Optimization of College Art Course Resources [J]. Journal of Hubei University of Science and Technology, 2014 (7).

[3] Shu Jinhong. Reflections on the Integration of Information Technology and College Art Courses [J]. Journal of Lishui University, 2005 (2).

[4] Li Wei. Cross-border Integration-The Curriculum Reform of the New Media Art Design Discipline of Guangzhou Academy of Fine Arts [J]. Cross-border Integration, 2005 (2).

[5] Li Sen and Liu Shujuan. The Professional Characteristics of Fine Arts in the Background of New Art Curriculum Reform [J]. Journal of Fuyang Teachers College, 2008 (6).

[6] Sha Ri Na. Analysis of Path of Strengthening the Integration and Development of New Media in Colleges and Universities under the Great Propaganda Pattern [J]. Ideological Education Research, 2016 (1). 